\title{
Monitoring of Power Factor for Induction Machines Using Estimation Techniques
}

\author{
Mohammadali Khodapanah \\ Brunel University London \\ Mohammadali.Khodapanah@Brunel.ac.uk
}

\author{
Ahmed F. Zobaa \\ Brunel University London \\ azobaa@ieee.org \\ M. H. Hakimie Rozlan \\ Brunel University London \\ Mohd.Binmohdrozlan@Brunel.ac.uk
}

\author{
Maysam Abbod \\ Brunel University London \\ maysam.abbod@brunel.ac.uk
}

\begin{abstract}
Power factor is a significant element in power systems which is defined as the angle difference between voltages and currents that produces power fluctuation between sources and loads. Since, $40-50 \%$ of consumption of electrical power in industry is induction machines which are inductive loads, monitoring of the power factor is necessary in order to protect systems. To monitor the power factor on induction machines, it would require both voltage and current waveforms measurement in order to apply the displacement method which require equipments. In this paper, we present a mathematical method using Kriging to determine the operating power factor for an induction machine. Estimation of the operating power factor would be effectively implemented for under load detection and compensation for improving the power quality. Experimental results will be indicated to substantiate the feasibility of the proposed methods.
\end{abstract}

Index Terms--Induction machine, Kriging analysis, Power factor, Exponential model.

\section{INTRODUCTION}

Power factor is a unity of power utilization by a load and is well-known as a ratio of power used in power distribution. The smaller power factor makes a higher current by the load and it produces a power fluctuation between sources and loads which is not efficient for power supplier [1], [2], [3].

The power supplier always tries to make a reasonable power factor above 0.8 or 0.9 . Since, $40-50 \%$ of consumption of electrical power in industrial are induction machines which are inductive loads, they make a poor power quality because loads especially in industrial are on and off for indefinite periods of time and create a power factor variation [4], [5].

Indeed, power factor has a significant role in induction machines because by variation of induction machine load, power factor increases and decreases exponentially. In particular, at light loading power factor is lower than desired point. Due to this issue, there has been a lot of focus on protection of induction machine's power factor at low and medium voltages. Although, there are protection devices for monitoring of the motor current and voltage like current overload, over/under voltage, in this research, one of the interesting elements is to monitor the operating power factor which is also defined as a cos $\phi$ of induction machine [6], [7].

Generally, to monitor the operating power factor of the induction machine, either measurement of voltage and current waveforms are required in order to measure the angle difference between voltage and current with the displacement method or measurement of the voltage, current and active power in root mean square value. Therefore, those methods need both voltage and current with required operating devices which are not economical [8], [9]. In this research, we present a method using Kriging to determine the operating power factor for the induction machine. The Kriging requires no voltage and current sensors and no active power measurement. The Kriging method only requires some measured point of power factor and current as an input data and also the nominal current which is on induction machine nameplate, can be used for loading calculation. Those input data will be measured once by current and power factor meter synchronously. Therefore measured data creates a curve model to the kriging and then the proposed method fit the existed curve model to the own model and build an equation. Consequently, by the equation, power factor can be estimated at any desired points [10], [11].

Hence, Kriging can provides a low-cost solution. For detecting low loading conditions, power factor is more reliable than the motor current-based approaches as will be described in details later. Power factor is particularly useful for applications like under-load protection of pumps and power factor compensation for improving the power quality.

In this paper, three ways of detecting the power factor will be explained. One is the zero crossing method by using measured current and voltage waveforms. The second method is using instantaneous power measurement by applying the basic formula. The third method is the Kriging analysis which is a significant estimation method that tries to estimate power factor at any loading conditions that will be discussed later.

In addition, explanation of a three phases induction machine, coupled to the dynamometer as a loading in terms of measuring actual power factor at different load. Finally, comparative output results from methods are going to be examined in order to substantiate the feasibility of Kriging method.

\section{POWER FACTOR ESTIMATION USING KRIGING METHOD}

Kriging analysis is an advanced geostatistical procedure, which is recognized as an interpolation technique. Indeed, the Kriging method estimates unknown values based on nearby observation and it minimizes the error of estimated values. 


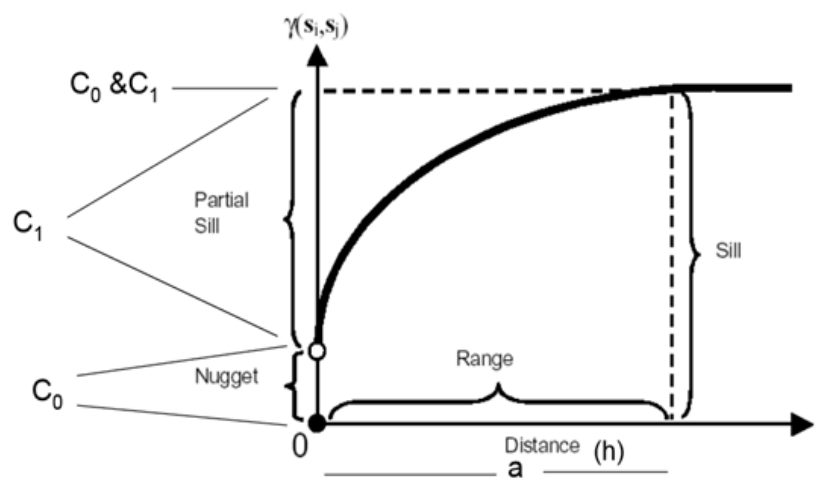

Fig. 1. Explanation of variogram graph

The significant key point of kriging is using a semivariogram model to determine the spatial interpolation accuracy. The semi-variagram model includes the linear, exponential, Gaussian and spherical model. Generally, the variagram model will be selected based on the existed curve. [12].

Since exponential model from Fig. 1, is similar to existed curve (1), it can be applied as a semi-variogram model for power factor estimation properly.

where $C_{0}$ is a nugget and semi-variance at distance that represents a micro scale or measurement errors. $a$ is a range that represents the spatially correlated portion and distance at which levels off. $C_{0}+C_{1}$ is a sill that semi-variance at which leveling takes place. $h$ is a variable separated with distance.

The exponential variogram equation:

$\gamma(i)=\mathrm{PF}_{\mathrm{m}} *\left(1-\mathrm{e}^{\frac{-3 h}{\mathrm{~L}_{\mathrm{m}}}}\right)$

where $P F_{m}$ is a minimum measured power factor, $\mathrm{h}$ is the matrix distance between each loading point, $L m$ is a maximum loading point and $\chi(i)$ is semi-variagram of exponential model.

Hence, from equation (2) langrage multiplayer is applied to obtain the weight coefficient $W_{i}$.

$\left[\begin{array}{c}\mathrm{W}_{1} \\ \mathrm{~W}_{2} \\ \vdots \\ \mathrm{W}_{\mathrm{n}} \\ \lambda\end{array}\right]=\left[\begin{array}{ccccc}\gamma_{11} & \gamma_{12} & \cdots & \gamma_{1 \mathrm{n}} & 1 \\ \gamma_{21} & \gamma_{22} & \cdots & \gamma_{2 \mathrm{n}} & 1 \\ \vdots & \vdots & \ddots & \vdots & \vdots \\ \gamma_{\mathrm{m} 1} & \gamma_{\mathrm{m} 2} & \cdots & \gamma_{\mathrm{mn}} & 1 \\ 1 & 1 & \cdots & 1 & 0\end{array}\right]^{-1} \cdot\left[\begin{array}{c}\gamma_{10} \\ \gamma_{20} \\ \vdots \\ \gamma_{\mathrm{n} 0} \\ 1\end{array}\right]$

Equation (2) is a langrage multiplication where $W_{i}$ is $(m \times 1$ matrix $)$ the weight of actual and estimated points which is unknown. $\gamma_{i}$ is $(m \times n$ matrix $)$ output of the semi-variagram function. $\gamma_{\mathrm{n} 0}$ is a vector $(\mathrm{m} \times 1)$ between the unknown loading points and observed loading points. Thus the weights $\mathrm{W}_{1}, \mathrm{~W}_{2}, \ldots, \mathrm{W}_{\mathrm{n}}$ and $\lambda$ can be evaluated, where $\lambda$ is useful in calculating the variance. The interpolation of unknown value at a point $F$ is then calculated from (3):

$\mathrm{PF}=W_{1} F_{1}+W_{2} F_{2}+W F_{3}+\cdots W_{n} F_{n}$ where $F_{i}$ are the PF at known locations.

\section{POWER FACTOR ESTIMATION USING ZERO CROSSING METHOD}

One of the remarkable methods to monitor power factor is the zero crossing method where it is required a measurement of the supply voltage and the motor current waveforms and also a sensor in order to distinguish the differences between voltage and current waveforms. In this method, the voltage is considered as a reference and therefore the displacement in the zero crossing by current give power factor [6], [13].

For instance, in the $50 \mathrm{~Hz}$ supply, the period of voltage and current signals would be $20 \mathrm{~ms}$, which covers $360^{\circ}$. If there is $\mathrm{a} \pm \Delta t \mathrm{~ms}$ differences between the current and voltage zero crossing, then the power factor given by (4).

$P F=\operatorname{Cos}\left(\frac{ \pm \Delta t}{T} \times 360^{\circ}\right)$

where $\pm \Delta t$ is a distance between voltage and current waveforms. $T$ is the duration one cycle and is the reciprocal of the frequency.

\section{POWER FACTOR ESTIMATION USING INSTANTANEOUS POWER}

Another significant method to monitor power factor can be via the instantaneous power measurement method. In this method, the power factor will be calculated by the instantaneous power measurement per phase in point by point multiplication of the two waveforms along the synchronized supply voltage and the motor current measurements by the oscilloscope [9]. Therefore, the average power $(\bar{P})$ per phase from the measurement was used. Then by this method, the power factor is given by (5)

$P F=\frac{\bar{P}}{V \times I}$

where $\bar{P}$ is average active power. $\mathrm{V}$ is the rms voltage supply and I is the rms motor current.

\section{EXPERIMENTAL STUDY}

\section{A. Experimental setup}

To verify the proposed method, the fallowing experimental setup was used, with motor specification shown in table I where it is considered a small three phase squirrel cage motor as a test motor from Feedback Instrument Company in Laboratory. 
TABLE I

SPECIFICATION OF Three PHASE SQUiRREL CAGE Motor

\begin{tabular}{cc}
\hline Nominal Voltage & $380 \mathrm{~V} / 50 \mathrm{HZ}$ \\
Nominal Current & $0.6 \mathrm{~A}$ \\
Rated Power & $250 \mathrm{~W}$ \\
Rated Speed & $2770 \mathrm{RPM}$ \\
Rated Power Factor & 0.8 \\
\hline
\end{tabular}

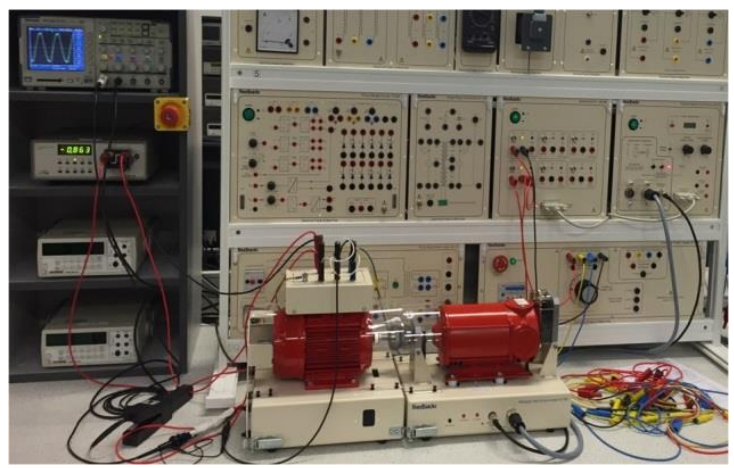

Fig. 2. Experimental Setup

Fig. 2, shows a test motor with a $250 \mathrm{~W}$ supplied from 50 $\mathrm{HZ}$ and a dynamometer as a load motor with a size of $250 \mathrm{~W}$ directly coupled to test motor [10]. The motor load can be controlled from no-load to over-load conditions either manually or by feedback instrument software [14].

In this case, two devices were considered for power factor measurement. One is a power analyser in order to show an actual power factor and the second devices are oscilloscope in terms of using the zero crossing and instantaneous power methods to obtain the power factor.

In this experimental study, we tried to measure current and power factor in 21 points at different loadings as samples. Then, 13 points is preferred to indicate for validation of zero crossing, instantaneous power and Kriging method. From the experimental measurements, 8 measured points out of 21 points are used for input of Kriging method and then the output of Kriging will be validated by considering measured points in table II.

To indicate the value of motor load, measured current points were divided by the nominal current from motor nameplate.

TABLE II

MEASUREMENT OF POWER FACTOR AND MOTOR CURRENT

\begin{tabular}{cccc}
\hline no & Loading \% & Measured I & Measured PF \\
\hline 1 & 50.000 & 0.275 & 0.507 \\
2 & 60.000 & 0.335 & 0.698 \\
3 & 70.000 & 0.388 & 0.782 \\
4 & 80.000 & 0.442 & 0.827 \\
5 & 85.000 & 0.468 & 0.841 \\
6 & 95.000 & 0.519 & 0.865 \\
7 & 100.000 & 0.550 & 0.871 \\
8 & 105.000 & 0.579 & 0.882 \\
9 & 115.000 & 0.631 & 0.895 \\
10 & 120.000 & 0.661 & 0.899 \\
11 & 125.000 & 0.685 & 0.904 \\
12 & 135.000 & 0.743 & 0.910 \\
13 & 140.000 & 0.772 & 0.911 \\
\hline
\end{tabular}

B. Zero crossing method using scope

As previously explained about theory of zero crossing method, it will be implemented using scope. In this section, using zero crossing by scope, it is needed to adjust the voltage and current waveforms to the zero crossing and then applying to the cursor bottom in order to obtain $\pm \Delta t$ which is a distance between voltage and current [6], [15].

to obtain acurate $\pm \Delta t$, the dash sign on the blue line must be located on zero crossing by position volume and then read the $\pm \Delta t$ from scope.

Fig. 3, shows the zero crossing method using scope in $45 \%$ loading where $\pm \Delta t$ is $4 \mathrm{~ms}$ and by applying to (6), power factor is:

$$
\mathrm{PF}=\cos \left(\frac{4 \mathrm{~ms}}{20 \mathrm{~ms}} \times 360^{\circ}\right)=0.309
$$

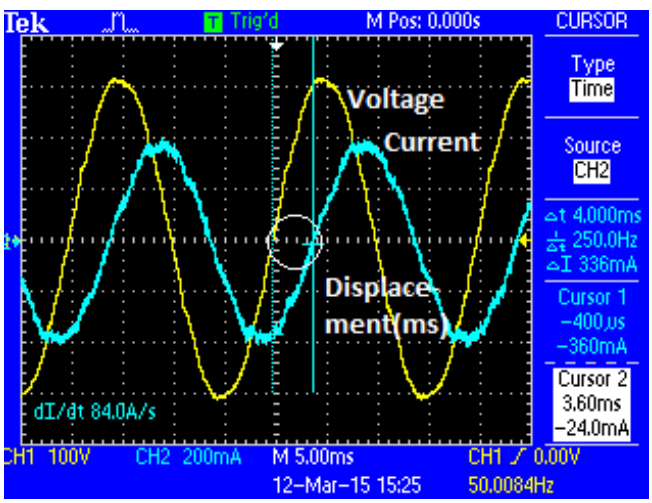

Fig. 3. Power Factor Measurement Using Zero Crossing at $45 \%$ Loading

Therefore, by increasing load at each step, current will be moved towards the voltage waveforms that in consequence makes a low $\pm \Delta t$ and good power factor.

\section{Instantaneous power method using scope}

From Fig. 4, using instantaneous power will be applied by power analyzer bottom in scope. Then, it is given power waveform with rms value [6], [15].

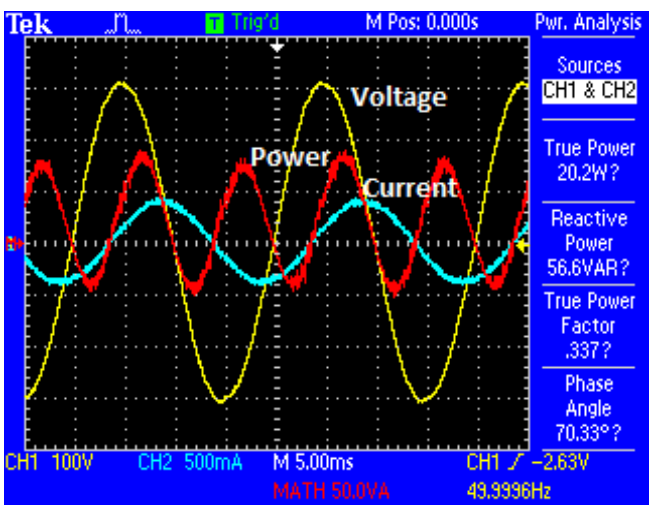

Fig. 4. Power Factor Measurement Using Instantaneous Power 
It is indicated a power $\overline{\mathrm{P}}=20.2 \mathrm{~W}$ in $45 \%$ loading and the rms values of the supply voltage and motor current, $220 \mathrm{~V}$ and 0.272 A respectively. Therefore, the Power Factor power, using (7)

$$
\mathrm{PF}=\frac{20.2}{220 * 0.272}=0.337
$$

Consequenly, it is observed that the calculated power factor is the same as the true power factor from scope in Fig. 4.

\section{DISCUSSION AND ANALYSIS}

As the measured current motor and power factor are shown in Fig. 5, it can be stated that loading has a linear relationship with current where loading is calculated from measured current over Nominal current. Therefore, motor current provides a good overview of the motor load. However, at low loads between $40 \%$ and $80 \%$ of current load, the non-linear curve of the power factor provides a better resolution for power factor protection than the motor current. As a result, power factor is more reliable than motor current in terms of under load protection [16], [17].

There is a tendency to believe that all induction machine power factor have an identical curve which is similar to the exponential mathematical model. This similarity helps using curve fitting methods in order to build an equation for finding any desired points on the curve [6], [18]. However, using curve fitting method requires some sample points for the $\mathrm{x}$ and $\mathrm{y}$ axis. Having the samples as $\mathrm{x}$ and $\mathrm{y}$ coordinates, it is required to measure motor current and motor power factor by a power factor meter where $\mathrm{x}$ axis is considered measured current over nominal current as a loading and $\mathrm{y}$ axis as a power factor.

Once those required values are measured, power factor can be monitored without considering any operating power factor meter.

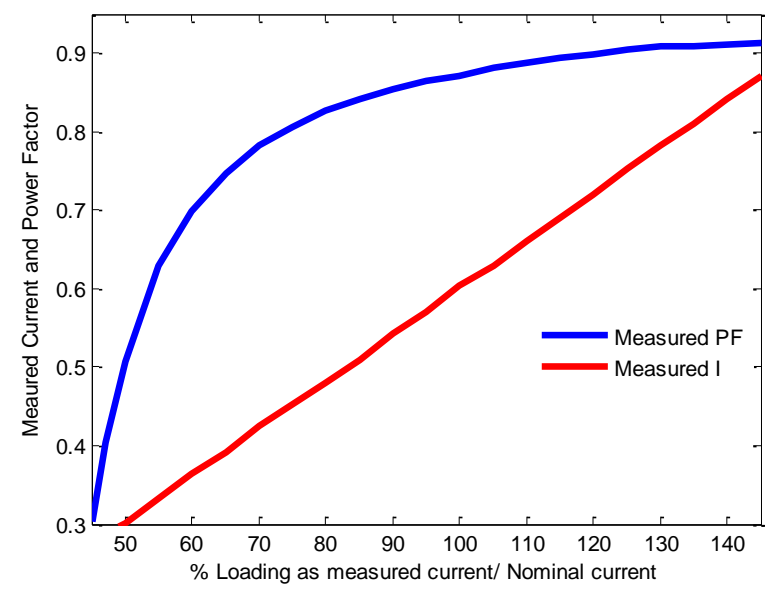

Fig. 5. Operating Current and Power Factor Curve of Motor
TABLE III

POWER FACTOR BY ZERO CROSSING METHOD

\begin{tabular}{ccccc}
\hline no & $\begin{array}{c}\text { Loading } \\
\text { \% }\end{array}$ & $\begin{array}{c}\text { Measured } \\
\text { PF }\end{array}$ & $\begin{array}{c}\text { Estimated } \\
\text { PF }\end{array}$ & $\begin{array}{c}\text { Error } \\
\text { \% }\end{array}$ \\
\hline 1 & 50.000 & 0.507 & 0.482 & 4.970 \\
2 & 60.000 & 0.698 & 0.729 & 4.441 \\
3 & 70.000 & 0.782 & 0.809 & 3.453 \\
4 & 80.000 & 0.827 & 0.809 & 0.497 \\
5 & 85.000 & 0.841 & 0.844 & 0.392 \\
6 & 95.000 & 0.865 & 0.876 & 1.306 \\
7 & 100.000 & 0.871 & 0.876 & 0.609 \\
8 & 105.000 & 0.882 & 0.876 & 0.646 \\
9 & 115.000 & 0.895 & 0.905 & 1.095 \\
10 & 120.000 & 0.899 & 0.905 & 0.645 \\
11 & 125.000 & 0.904 & 0.905 & 0.089 \\
12 & 135.000 & 0.910 & 0.930 & 2.176 \\
13 & 140.000 & 0.911 & 0.930 & 2.064 \\
Total Error & & & $\mathbf{2 2 . 3 8 3}$ \\
\hline
\end{tabular}

TABLE IV

POWER FACTOR By INSTANTANEOUS POWER METHOD

\begin{tabular}{ccccc}
\hline no & $\begin{array}{c}\text { Loading } \\
\text { \% }\end{array}$ & $\begin{array}{c}\text { Measured } \\
\text { PF }\end{array}$ & $\begin{array}{c}\text { Estimated } \\
\text { PF }\end{array}$ & $\begin{array}{c}\text { Error } \\
\text { \% }\end{array}$ \\
\hline 1 & 50.000 & 0.507 & 0.528 & 4.182 \\
2 & 60.000 & 0.698 & 0.723 & 3.524 \\
3 & 70.000 & 0.782 & 0.810 & 3.568 \\
4 & 80.000 & 0.827 & 0.826 & 2.646 \\
5 & 85.000 & 0.841 & 0.863 & 2.580 \\
6 & 95.000 & 0.865 & 0.885 & 2.301 \\
7 & 100.000 & 0.871 & 0.900 & 3.353 \\
8 & 105.000 & 0.882 & 0.903 & 2.392 \\
9 & 115.000 & 0.895 & 0.914 & 2.156 \\
10 & 120.000 & 0.899 & 0.914 & 1.691 \\
11 & 125.000 & 0.904 & 0.922 & 2.035 \\
12 & 135.000 & 0.910 & 0.929 & 2.132 \\
13 & 140.000 & 0.911 & 0.930 & 2.130 \\
\hline
\end{tabular}

TABLE V

POWER FACTOR BY KRIGING METHOD

\begin{tabular}{ccccc}
\hline no & $\begin{array}{c}\text { Loading } \\
\text { \% }\end{array}$ & $\begin{array}{c}\text { Measured } \\
\text { PF }\end{array}$ & $\begin{array}{c}\text { Estimated } \\
\text { PF }\end{array}$ & $\begin{array}{c}\text { Error } \\
\text { \% }\end{array}$ \\
\hline 1 & 50.000 & 0.507 & 0.467 & 7.830 \\
2 & 60.000 & 0.698 & 0.688 & 1.418 \\
3 & 70.000 & 0.782 & 0.776 & 0.818 \\
4 & 80.000 & 0.827 & 0.805 & 0.008 \\
5 & 85.000 & 0.841 & 0.836 & 0.547 \\
6 & 95.000 & 0.865 & 0.860 & 0.578 \\
7 & 100.000 & 0.871 & 0.868 & 0.390 \\
8 & 105.000 & 0.882 & 0.877 & 0.578 \\
9 & 115.000 & 0.895 & 0.890 & 0.559 \\
10 & 120.000 & 0.899 & 0.894 & 0.556 \\
11 & 125.000 & 0.904 & 0.900 & 0.443 \\
12 & 135.000 & 0.910 & 0.908 & 0.275 \\
13 & 140.000 & 0.911 & 0.909 & 0.198 \\
Total Error & & & $\mathbf{1 4 . 1 9 9}$ \\
\hline \multicolumn{5}{l}{}
\end{tabular}

Although most modern electrical machines usually measure both voltage and current and provide power factor measurements that may not be required for low cost calculation of power factor, the proposed method is aimed at applications where such devices are too costly Therefore, this constraint provides the intended benefit of the proposed method.

Hence, from table III,IV and V it can be understood that the results of zero crossing and power instantaneous methods have differences to the actual power factor with total errors about $\mathbf{2 2 . 3 8 3 \%}$ and $\mathbf{3 4 . 6 8 9 \%}$ respectively. In contrast, table 
$\mathrm{V}$ is indicated that the results from Kriging method is fitted to the actual power factor with acceptable errors about $14.199 \%$.

Zero crossing and instantaneous power methods not only indicate high errors compared with the measured Power factor from power analyser but also voltage and current sensor are required in order to detect the distance between voltage and current waveforms at operating time for power factor calculation. In addition, in instantaneous power method, power meter devices with synchronised voltage are required. However, Kriging do not required them at operating time and it is a cheaper solution for monitoring power factor where Kriging estimated values with less error compare to measured values. Therefore, zero crossing and instantaneous power methods can not have a high accurate at operating times.

Despite the fact that the proposed method has needed some sample of power factor measurement, power factor meter at operating times would not be required constantly. The proposed method only needs some points of measured power factor once at an operating time unlike other methods which need to be connected at operating time continually.

Consequently, Kriging can be an effective technique for estimation of induction machines power factor in particular for those factories that have some identical induction machines.

\section{CONCLUSION}

The power factor in induction motors is recognized as an important element because having a lower power factor in induction motor means consuming more reactive current than active current thus creates huge power quality problems in grid systems. Due to this issue, a lot of focus must be on it. To monitoring power factor, it can be either using constant measurement devices or using a remarkable mathematical model. Indeed, using power factor meter, it is required the both voltage and current measurement with sensors in order to apply zero crossing displacement method which provides a huge cost in terms of equipment prices and maintenance particularly for those factories that many motors are working. However, using the mathematical model can provide a low cost solution. In this research, the kriging method is presented to estimate power factor at any loading especially at under load conditions needing to be improvement. The proposed method requires some measured power factor and current as input data. Once done, Kriging can estimate the power factor at any desired point for considered motor continually without using operating measurement devices. Although Kriging requires some power factor and current measurement as an input data, it will be done only once and it does not requires any measurement devices with sensors unlike zero crossing and instantaneous methods that need operating measurement devices constantly. As a result, Kriging provides a cheaper solution for under load protection and also power factor compensation to improve power quality with acceptable results compared to the measured data.

\section{REFERENCES}

[1] A. Bhatia, Power Factor in Electrical Energy Management, Meadow: PDHonline Course, 2012.

[2] A. Accetta, F. Alonge, M. Cirrincione, M. Pucci and A. Sferlazza, "Parameter identification of induction motor model by means of State Space-Vector Model Output Error Minimization," IEEE International Conference on Electrical Machines (ICEM), pp. 843 - 849, Sep 2014.

[3] F. Alonge, M. Cirrincione, F. D'Ippolito, M. Pucci and A. Sferlazza, "Parameter Identification of Linear Induction Motor Model in Extended Range of Operation by Means of Input-Output Data," IEEE Transactions on Industry Applications, vol. 50, no. 2, pp. 959-972, March/April 2014.

[4] L. Guo, Y. Cheng, L. Zhang and H. Huang, "Research on Power -Factor Regulating Tariff Standard," IEEE International Conference on Electricity Distribution, pp. 1 - 5, Dec 2008.

[5] K. Zhou and L. Cai, "Online Measuring Power Factor in AC Resistance Spot Welding," IEEE Transactions on Industerial Electronics, , vol. 61, pp. 575-582, Jan. 2014.

[6] A. Ukil, R. Bloch and A. Andenna, "Estimation of Induction Motor Operating Power Factor From Measured Current and Manufacturer Data," IEEE Transactions on Energy Conversion , vol. 26, no. 2, pp. 699-706, June 2011.

[7] K. Salmon, H. Perera and M. Toulabi, "A Grid-Connected Induction Machine Capable of Operation at Unity and Leading Power Factor," IEEE Energy Conversion Congress and Exposition (ECCE), pp. 238 245 , Sep 2013.

[8] M. H. Haque, "Determination of NEMA Design Induction Motor Parameters From Manufacturer Data," IEEE Transaction on Energy Conversion, vol. 23, no. 4, pp. 997-1004, December 2008.

[9] J. Marcondes and C. Guimar aes, "Parameter Determination of Asynchronous Machines From Manufacturer Data Sheet," IEEE Transaction on Energy Conversion, vol. 29, no. 3, pp. 689-697, Sep 2014.

[10] A. Sarkar and S. Sengupta, "A Novel Instantaneous Power Factor Measurement Method Based on Wavelet Transform," IEEE Power India Conference, pp. 1-6, 2006.

[11] T. Phumiphak and C. Chat-uthai, "Estimation of Induction Motor Parameters Based on Field Test Coupled with Genetic Algorithm," IEEE International Conference on Power System, vol. 2, pp. 1199 1203, 2002.

[12] W. Huizan, Z. Ren and L. Kefeng , "Improved Kriging Interpolation Based on Support Vector Machine and Its Application in Oceanic Missing Data Recovery,"IEEE in International Conference on Computer Science and Software Engineering, Wuhan, Hubei, 2008.

[13] J. Susanto and S. Islam, "Estimation of Induction Motor Parameters Using Hybrid Algorithms for Power System Dynamic Studies," IEEE Power Engineering Conference(AUPEC), pp. 1-6, Oct 2013.

[14] Feedback. Instrument, Powerframes Components Core System, Sussex, 2013.

[15] Tektronix, TPS2000 Series Digital Storage Oscilloscope User Manual, Beaverton, 2010.

[16] M. Morad, A. Abdelaziz and E. Saadany, "Estimation of Induction Motor Single-Cage Model Parameters from Manufacturer Data,"IEEE Power and Energy Society General Meeting (PES), pp. 1 - 5, July 2013.

[17] V. Kumar Ghial,, L. Mohan Saini and J. Singh Saini, "Parameter Estimation of Permanent-Split Capacitor-Run Single-Phase Induction Motor Using Computed Complex Voltage Ratio," IEEE Transaction on Industrial Electronics, vol. 61, no. 2, pp. 682-692, Feb 2014.

[18] Z. Gmyrek, A. Boglietti and A. Cavagnino, "Estimation of Iron Losses in Induction Motors:Calculation Method, Results, and Analysis," IEEE Transaction on Industrial Electronics, vol. 57, no. 1, pp. 161-171, Jan 2010 . 